\title{
Şimşir ormanlarında bazı toprak ve iklim özelliklerinin Cylindrocladium pseudonaviculatum'in epidemi oluşturması üzerine etkilerin araştırılması: Taşlıca ve Tütüncüler örnekleri
}

\author{
Investigation of the effects of some soil and climate properties on the epidemic of Cylindrocladium pseudonaviculatum \\ in Boxwood forests: the cases of Taşlıca and Tütüncüler
}

\section{Mimar Sinan ÖZKAYA}

Orman Genel Müdürlüğü, Artvin Orman Bölge Müdürlüğü, Artvin.

\section{Eser Bilgisi / Article Info \\ Araştırma makalesi / Research article DOI: $10.17474 /$ artvinofd.788047}

Sorumlu yazar / Corresponding author Mimar Sinan ÖZKAYA

e-mail: mimarsinan08@hotmail.com

Geliş tarihi / Received

30.08.2020

Düzeltme tarihi / Received in revised form

08.09.2020

Kabul Tarihi / Accepted

08.09.2020

Elektronik erişim / Online available

17.09.2020

\section{Anahtar kelimeler:}

Buxus sempervirens

Cylindrocladium pseudonaviculatum

Şimşir güvesi

Toprak özellikleri

Keywords:

Buxus sempervirens

Cylindrocladium pseudonaviculatum

Boxwood moth

Soil properties

\begin{abstract}
Özet
Artvin Orman Bölge Müdürlüğü Şimşir (Buxus sempervirens) ormanlarında Cylindrocladium pseudonaviculatum'in epidemi yapmasının ve şimşir ağaçlarının kurumasına toprak yapısının ve iklim özelliklerinin etkilerinin incelenmesi amacı ile bu çalışma yapılmıştır. B. sempervirens Artvin'de yaklaşık 15 bin hektarlık bir alanda yayılış göstermektedir. Bu alanlarda şimşir fungal hastalıkları (Cylindrocladium pseudonaviculatum) ve Şimşir güvesi (Cydalima perspectalis) kurumalara neden olmuştur. Gerek mantar gerekse böcek zararının görülmesinin kuraklıktan ve topraktaki bazı elementlerin azalmasından kaynaklanabileceği düşüncesiyle, şimşir kurumalarının yoğun olduğu ormanlık alanlarda ve sağlıklı yetiştiği alanlardaki sıcaklık ve yağış değerleri ile bazı toprak özellikleri incelenmiştir. Şimşir ağaçlarının kuruma gösterdiği ve sağlıklı yetiştiği sahalardan alınan toprak özellikleri ile sıcaklık ve yağış değerlerinin farklılık gösterip göstermediği bağımsız iki örneklem T-Testi ile test edilmiştir. Çalışma sonucunda alanlar arasındaki farklııkların toprak özellikleri bakımından önemsizken, sıcaklık ve yağış değerleri bakımından anlamlı düzeyde farklı $(p<0.05)$ olduğu belirlenmiştir. Hastalıklı alanlarda ortalama sıcaklık daha yüksek, ortalama yağış ise daha düşüktür. Sonuçlar şimşir ağaçlarında görülen kurumaların toprak özelliklerinden kaynaklanmadığını, sıcaklık ve yağış değerlerinin bu kurumalarda nispeten daha etkili olabileceğini göstermektedir.
\end{abstract}

\begin{abstract}
The overall objective of this study is to understand to what extend some soil properties and climatic properties cause an increased population of Cylindrocladium pseudonaviculatum (Buxus blight), and accordingly impacting the box trees to kill in some 15 thousand ha forest of Buxus sempervirens (Boxwood) in Artvin. Furthermore, the fungal diseases (Cylindrocladium pseudonaviculatum) and Boxwood moth (Cydalima perspectalis) caused mortality of boxwood in these areas. Since the climate change and some soil properties might be a cause for the epidemic levels of insect and fungal species, this study was conducted, but predominantly towards in favor of some soil properties of the healthy stands and the stands suffering from the insect and these fungus, both stands dominated with boxwood. Whether the soil properties and temperature and rainfall values differ from the stands where boxwood trees were healthy and unhealthy was tested by two independent samples T-Test. As a result of the study, it was determined that the differences between the healthy and unhealthy stands were insignificant in terms of soil properties, but significant $(p<0.05)$ in terms of temperature and rainfall values. The results indicated that the mortality seen in boxwood trees was not due to soil properties, but temperature and precipitation differences could be effective in it as average temperature was higher in disease effected stands and average rainfall was lower compared to healthy stands.
\end{abstract}

\section{Giriş}

Anadolu şimşiri (Buxussempervirens L.) ormanlarımızın yanı sıra süs bitkisi ve bahçelerde dekoratif bir ağaç olarak ta yetişmektedir. Şimşirgiller (Buxaceae) familyasının bir türü olup her dem yeşil, sık dallı, çalı veya ağaç halinde, odunsu, ve ekonomik öneme sahiptir. Şimşir gölgeye dayanıklı, yavaş büyüme gösteren ve besin maddelerince zengin toprakları tercih etmektedir. Şimşir odunu kolay çürümediği, böcek ve mikroorganizmalara dayanıklııı̆ından dolayı kaşık, makine yatakları, tavla pulu, oyuncak, havan, tarak, tabak, ağızlık, mekik ve süs eşyaları gibi değişik alanlarda kullanılan bir ağaç türüdür (Türkyılmaz ve Vurdu 2003). Almanya, Bulgaristan, Fransa, Gürcistan, İspanya, Portekiz ve Türkiye yayılış gösterdiği ülkelerdir. Türkiye'deki yayılışını Karadeniz ve Marmara bölgesinde yoğun olmakla birlikte Adana, Antalya, Bolu, Denizli, Hatay, Karabük, Kastamonu, 
Kahramanmaraş, Kocaeli, Muğla ve Osmaniye'de yapmaktadır (Altunışık ve ark. 2017, Ateş ve ark. 2010, Lehtijärvi ve ark. 2014). Orman Genel Müdürlüğü verilerine göre şimşir Ülkemizde 20424 ha.'Iık bir alanda yayılış göstermektedir (URL 1). Artvin ilinde birçok alanda şimşir ağaçlarının görüldüğü belirtilmektedir (Eminağaoğlu ve Anşin 2003, Eminağaoğlu ve ark. 2018).

Türkiye'de, şimşir alanları gerek insanlar, gerekse hastalık ve böcek zararından dolayı büyük tahribatlara maruz kalmış ve küçük gruplar halinde yetişen bir ağaç türü haline gelmiştir (Symmes 1984). Cylindrocladium buxicola Henricot (Henricotve Culham 2002), Cylindrocladium pseudonaviculatum (Şimşir yaprak yanıklığı) (Crous ve ark.2002) fungal hastalıklar ve Cydalima perspectalis (Şimşir güvesi) (Walker 1859) tırtılları şimşir ağaçları üzerinde en fazla olumsuz etkileri olan biyotik faktörlerdir. Cy. pseudonaviculatum fungal etmeni ilk kez 2011 yılında Trabzon ve Artvin şimşir alanlarında tespit edilmiş ve kısa bir zamanda şimşir alanlarının \%90'nına yayılmıştır (Lehtijärvive ark. 2014). Cy. pseudonaviculatum hastalık etmeninin Artvin ilinde şimşirlerin kurumalarına neden olan en önemli etken olarak belirtilmektedir. Bu patojen bitkideki gelişimini bir haftalık kısa bir sürede tamamlamaktadır. Enfeksiyon için yüksek rutubet ve bitkinin ıslak olması yeterli olup enfeksiyonu başlatacak sporlar rüzgârlarla, böceklerle, kuşlarla ve yağmurlarla uzak mesafelere taşınabilmektedir (Henricot ve ark. 2000, Henricot ve ark. 2008).

$\mathrm{Bu}$ patojen mantarlar, 2015 yılından itibaren zarar yapmaya başlayan C.perspectalis aracılığıyla ulaşamadığı sahalara da taşınmıştır. C.perspectalis (Walker 1859) (Lepidoptera: Crambidae) yabancı ve istilacı bir tür olup dünyadaki tüm şimşir alanlarının en önemli zararlılarından biridir (Leuthardtve ark. 2010, Göktürk ve ark. 2014, Hizalve ark. 2012, Göktürk. 2017, Burjanadze ve ark. 2019). C. perspectalis, Buxus sempervirens L. başta olmak üzere tüm Buxus türleri ile beslenmektedir.

Artvin Orman Bölge Müdürlüğü ormanları, zararlı organizmalar için Türkiye ile Gürcistan arasında geçiş noktası olarak kabul edilebilir. 2010 yılında Gürcistan Cumhuriyeti Batum ili şimşir ormanlarında şimşir yaprak yanıklığı hastalığının zararı görülmeye başlamış ve daha sonraki yıllarda şimşir ormanlarımıza gelerek zarar yapmaya başlamıştır. Şimşir güvesi ise Gürcistan'a bitişik olan Artvin Muratlı ilçesi üzerinden ülkemiz ormanlarına giriş yapmıştır. Asya kökenli olan bu zararlı, Artvin Şimşir ormanlarının tamamını etkisi altına alarak, önemli ölçüde zarara neden olmuştur.

2015 yılından önce bol yağışın ve nemli ortamın fazla olması nedeniyle, şimşir yanıklığı hastalıklarının yayılması ve etkisi fazla oranda görülmekteyken, 2016 yılından sonra kuraklığın artması, şimşir ormanlarının kuraklıktan su stresine girmesine neden olmuştur. Su stresine giren şimşir ormanları 2016 yılından itibaren de Cydalima perspectalis'in istilasına uğramış ve epidemi boyutuna gelmiştir. Kuraklık sonucu ağaç kurumalarının \%25'inde böcek zararı ve ağaç hastalıkların etken olduğu belirtilmektedir (Semerci ve ark. 2006, Şimşek ve ark. 2010a, 2010b). Kuraklık, su ve toprak yapısı sonucu besin stresi, ağaçların fizyolojisi ve fenolojisini olumsuz yönde etkilemektedir. Toprakta bulunan kullanılabilir su durumu ve toprak özellikleri ile zararlı böceklere karşı ağaçların göstereceği pozitif direnç arasında doğrusal bir ilişki bulunmaktadır (Şimşek ve ark. 2006).

Şimşir alanlarında görülen kurumların nedeninin tam olarak anlaşılabilmesi için gerek hastalık gerekse zararlıların etkisiyle yoğun şimşir kurumalarının olduğu ormanlık alanlarda iklim kadar toprak özelliklerinin de ele alınması gerekmektedir. $\mathrm{Bu}$ çalışmada, $\mathrm{Cy}$. pseudonaviculatum'un epidemi yapmasında iklim özellikleri ile bazı toprak özelliklerindeki farklııktan kaynaklanıp kaynaklanmadığı araştırılmıştır.

\section{MATERYAL VE YÖNTEM}

\section{Materyal}

Bu çalışma, Artvin Orman Bölge Müdürlüğü, Artvin Orman İşletme Müdürlüğü'ne bağlı Taşlıca ve Tütüncüler Orman İşletme Şeflikleri sınırları içerisinde kurumaların olduğu ve sağlıklı Şimşir ağaçların bulunduğu sahalarda gerçekleştirilmiştir.

Cydalima perspectalis ile biyoteknik mücadele amacıyla zarar yaptığı sahalara asılan delta tipi tuzaklar ve 
dispenserler ile Cy. Pseudonaviculatum mantarlarını enfekte ettiği yapraklar çalışmanın ana materyalini oluşturmaktadır. Çalışmada, GPS, stereo mikroskop, plastik kaplar ve naylon poşet diğer materyal olarak yer almıştır.

\section{Yöntem}

Toprak örneklemesi katmanlı rastgele yönteme göre yapılmıştır. Araştırma alanı şimşir kurumalarının yoğun olarak görüldüğü ve şimşir kurumalarının olmadığı ve yükseltisi 400-550 metreler arasında değişen iki farklı katmana ayrılmıştır. Daha sonra bu katmanların her birinden rasgele yönteme göre seçilen 10 farklı noktada toprak çukurları açılmış ve $0-20 \mathrm{~cm}$ derinlik kademesinden toprak örnekleri alınarak bazı analizler için laboratuvara nakledilmiştir.
Toprak örneklerinin tekstür tayini Bouyoucos' un hidrometre yöntemine göre yapılmıştır. Organik madde miktarı 0.2 mm'lik elekten geçirilmiş 0.5 gr' lık örnekler üzerinden Walkley- Black' ın Islak yakma yöntemine göre yapılmıştır (Irmak 1972, Gülçur 1974). Toprak örneklerinin $\mathrm{pH}^{\prime}$ sI $1 / 2.5$ oranında toprak-saf su karışımında Orion 420 Adigital pH metresi ile ölçülmüştür (Gülçur 1974).

Ayrıca Şimşir yaprak yanıklığı hastalığı nedeniyle enfekte olan yapraklar ile dallar (Şekil 1) ıslak pamuğa sarılarak kilitli naylon poşet içine konulmuş ve sağlam şimşirlerin yapraklarında kışı geçiren Cydalima perspectalis'in larvaları (Şekil 2) ise plastik kaplarla Artvin Bölge Müdürlüğüne bağlı, Biyolojik Mücadele laboratuvarına getirilerek, mikroskop altında incelenerek türlerin tespiti yapılmıştır.

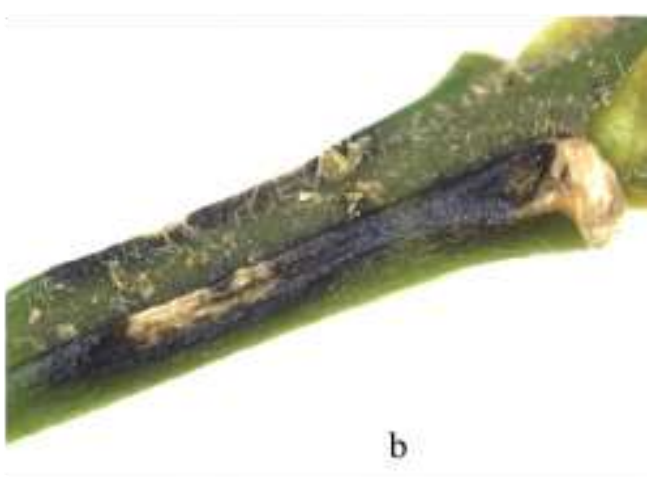

Şekil 1. Enfekte olmuş yaprak (a) ve dal (b) örnekleri
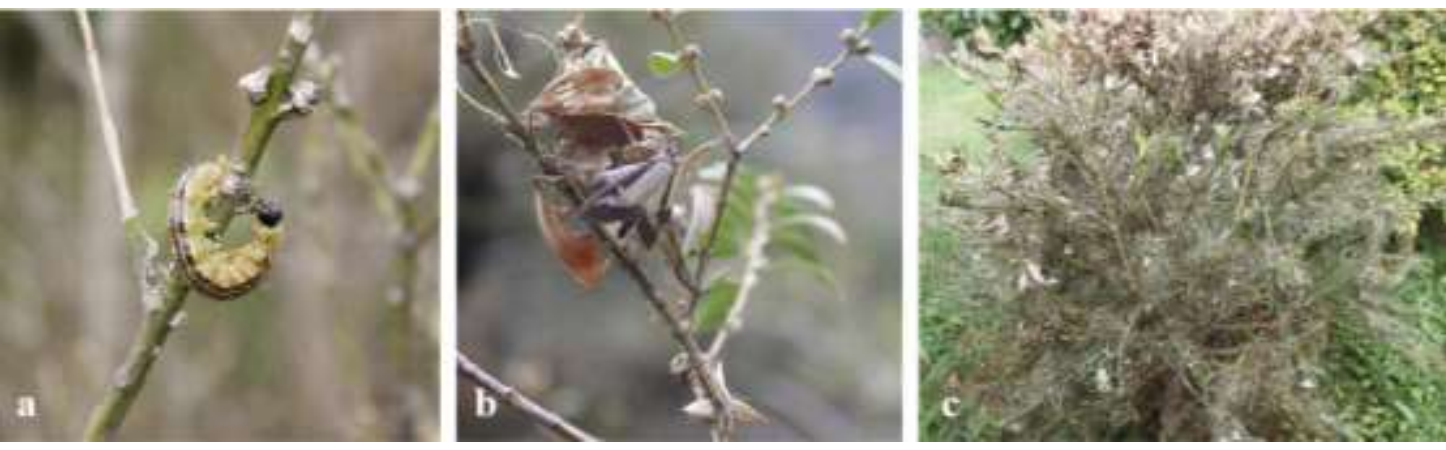

Şekil 2. Şimşir kelebeği larvası (a), ergini (b) ve zarar durumu (c)

Hastalıklı ve sağlıklı alanlar arasında toprak ve iklim özellikleri (ortalama yağış, ortalama sıcaklık, ortalama en yüksek sıcaklık, ortalama en düşük sıcaklık) bakımından fark olup olmadığını belirlemek amacıyla bağımsız iki örnek T-Testi kullanılmıştır.

\section{BULGULAR VE TARTIŞMA}

Kurumaların olduğu alanlarda yoğun olarak fungal hastalık etmenleri ve şimşir kelebeği görülmüştür. Kurumaların olduğu alanlar ile sağlıklı şimşir ağaçlarının olduğu alanlar arasında toprak özellikleri bakımından 
Şimşir ormanlarında bazı toprak ve iklim özelliklerinin Cylindrocladium pseudonaviculatum'in epidemi oluşturması üzerine etkilerin araştırılması: Taşlıca ve Tütüncüler örnekleri

önemli $(p<0.05)$ bir farkın olmadığı belirlenmiştir (Çizelge

1).

Çizelge1. Sağııkı ve hastalıklı alanlar arasında toprak özelliklerinin farklı olup olmadığına ilişkin yapılan Bağımsız İki Örneklem T-Testi Sonuçları

\begin{tabular}{|c|c|c|c|c|c|c|}
\hline \multirow{2}{*}{$\begin{array}{l}\text { Toprak ve İklim } \\
\text { Özellikleri }\end{array}$} & \multicolumn{2}{|c|}{ Levene's Test forEquality of Variances } & \multicolumn{4}{|c|}{ t-test for Equality of Means } \\
\hline & $\mathrm{F}$ & Sig. & $\mathrm{t}$ & df & Sig. (2-tailed) & Mean Difference \\
\hline $\mathrm{pH}$ & 1.69 & 0.211 & 2.00 & 18.00 & 0.061 & 0.34 \\
\hline$\mu \mathrm{S}$ & 0.08 & 0.787 & -1.66 & 18.00 & 0.114 & -42.89 \\
\hline Org. Mad (\%). & 8.76 & 0.008 & -1.25 & 18.00 & 0.228 & -0.94 \\
\hline Kum \% & 1.83 & 0.193 & 1.49 & 18.00 & 0.155 & 4.52 \\
\hline Kil \% & 7.21 & 0.015 & -0.99 & 18.00 & 0.335 & -3.15 \\
\hline Toz \% & 0.05 & 0.823 & -0.72 & 18.00 & 0.481 & -1.37 \\
\hline
\end{tabular}

$\mu \mathrm{S}:$ Elektriksel iletkenlik (siemens)

Kurumaların yoğun olduğu sahalarda kil miktarının, sağlıklı Şimşir bireylerinin bulunduğu sahalara oranla artış göstermesi (Çizelge 2), topraktaki su tutma kapasitesini ve nemliliğini artırması gerekirken, son yıllarda kurak mevsimlerin hüküm sürmesi nedeniyle, yağışın az olması ve taban suyunun çekilmesi ile bazı sahalarda su açığı ortaya çıkarak, Şimşirlerin su stresine girmesine neden olduğu söylenebilir.

Çizelge 2. Sağlıklı ve hastalıklı alanların toprak özelliklerine ilişkin istatistiksel değerler

\begin{tabular}{|c|c|c|c|c|c|}
\hline Toprak Özelliği & Saha Durumu & $\mathrm{N}$ & Ortalama & Standart Sapma & Standart Hata \\
\hline \multirow[b]{2}{*}{$\mathrm{pH}$} & Sağılılı Alan & 10 & 7.2580 & 0.45203 & 0.14294 \\
\hline & Hastalıklı Alan & 10 & 6.9210 & 0.28286 & 0.08945 \\
\hline \multirow[b]{2}{*}{$\mu \mathrm{S}$} & Sağlıklı Alan & 10 & 176.750 & 56.0274 & 17.7174 \\
\hline & Hastalıklı Alan & 10 & 219.640 & 59.3119 & 18.7561 \\
\hline \multirow[b]{2}{*}{ Org. Mad. } & Sağlıklı Alan & 10 & 4.5790 & 2.05578 & 0.65009 \\
\hline & Hastalıklı Alan & 10 & 5.5150 & 1.18346 & 0.37424 \\
\hline \multirow[b]{2}{*}{ Kum \% } & Sağlıklı Alan & 10 & 71.8190 & 4.78252 & 1.51237 \\
\hline & Hastalıklı Alan & 10 & 67.3010 & 8.34366 & 2.63850 \\
\hline \multirow[b]{2}{*}{ Kil \% } & Sağlıklı Alan & 10 & 14.0810 & 3.80931 & 1.20461 \\
\hline & Hastalıklı Alan & 10 & 17.2350 & 9.32001 & 2.94725 \\
\hline \multirow{2}{*}{ Toz \% } & Sağlıklı Alan & 10 & 14.0970 & 4.39503 & 1.38983 \\
\hline & Hastalıklı Alan & 10 & 15.4630 & 4.08316 & 1.29121 \\
\hline
\end{tabular}

$\mu \mathrm{S}$ : Elektriksel iletkenlik (siemens)

Çalışma sahasından alınan toprak numunelerinin fiziksel ve kimyasal özelliklerinin belirlenmesi sonucunda, sağılıkı ve hastalıklı sahalarda kumlu killi balçık, kumlu killi, hafif killi, balçık, ve kumlu balçık toprak türünde oldukları belirlenmiştir. Toprak tekstürü, bitki hayatiyle ilgili bulunan köklerin toprak içerisine girmesine karşı direnç, toprağın havalanması, suyun sızması ve hareket hızı, su tutma kapasitesi ile verimlilik gibi özellikler üzerinde etkilidir.
Bu konuda yapılan araştırmalarda, ince tekstürlü toprakların üst tabakalarında daha çok su tutulduğu ve buharlaşmaya maruz kalan üst toprak tabakalarından daha fazla su kaybı olabildiği ifade edilmiştir. Ağaçların topraktan alabileceği su miktarının azalması, ağaç gelişimini olumsuz etkilemesi, kuraklık ve su stresinin böcek salgınlarıyla ilişkisi konusunda yapılmış bazı araştırmalar da bu duruma işaret etmektedir (Christiansen ve Bakke 1997, Hanks ve ark. 1999, Williams 
ve Liebhold 2002, Bentzve ark. 2010, Öner ve ark. 2010, Şimşek ve ark. 2010, Laz ve ark. 2018).

Toprakların reaksiyonu "Hafif Alkali ve Nötr" olarak belirlenmiştir. Buna göre toprakların reaksiyonu genellikle "Nötr" özellik göstermiştir. Toprakların pH değerleri incelendiğinde bitki gelişimi açısından herhangi bir sorun olmadığı anlaşılmaktadır. Bitkilerin büyük bir çoğunluğu toprak reaksiyonu açısından hafif asit $(\mathrm{pH}$ 5.56.5) şartlarda en iyi yetişme koşullarına sahiptir.

Şimşir bireylerinin sağlıklı olduğu yerlerdeki topraklarda ortalama $\mathrm{pH}$ değerleri ile hastalıklı olan alanlarda ortalama pH değerleri incelendiğinde, analiz sonuçlarına göre hastalıklı ve sağlıklı alanlar arasında toprak özellikleri bakımından farklılık göstermediği anlaşılmıştır. Burada iklim faktörünün belirleyici olduğu düşünülmektedir.

Toprak özellikleri bakımından sağlıklı ve hastalığın yoğun olduğu alanlar arasında fark olmamasına karşın, yağış ve sıcaklık değerleri bakımından önemli farklııılar bulunmaktadır (Çizelge 3). Hastalıklı sahalarda ortalama sıcaklık değerlerinin sağlıklı alanlara göre daha yüksek, ortalama yağış ise daha düşük olduğu belirlenmiştir (Çizelge 4)

Çizelge 3. Sağlıklı ve hastalıklı alanlar arasında iklim özelliklerinin farklı olup olmadığına ilişkin yapılan Bağımsız Iki Örneklem T-Testi Sonuçları

\begin{tabular}{|c|c|c|c|c|c|c|}
\hline \multirow{2}{*}{ İklim Özellikleri } & \multicolumn{2}{|c|}{ Levene's Test forEquality of Variances } & \multicolumn{4}{|c|}{ t-test forEquality of Means } \\
\hline & $\mathrm{F}$ & Sig. & $\mathrm{t}$ & $d f$ & Sig. (2-tailed) & Mean Difference \\
\hline Ort. Sıcaklık & 43.11 & 0.000 & -2.94 & 18.00 & 0.009 & -0.69 \\
\hline Ort. Yağış & 42.70 & 0.000 & 2.94 & 18.00 & 0.009 & 74.25 \\
\hline Ort. En Yük. Sıc. & 43.11 & 0.000 & -2.94 & 18.00 & 0.009 & -0.69 \\
\hline Ort. En. D. Sic. & 37.26 & 0.000 & -2.93 & 18.00 & 0.009 & -0.67 \\
\hline
\end{tabular}

Çizelge 4. Sağııkı ve hastalıklı alanların iklim özelliklerine ilişkin istatistiksel değerler

\begin{tabular}{|c|c|c|c|c|c|}
\hline İklim Özelliği & Saha Durumu & $\mathrm{N}$ & Ortalama & Standart Sapma & Standart Hata \\
\hline Ortalama & Sağlıklı Alan & 10 & 12.9620 & 0.29386 & 0.09293 \\
\hline Sıcaklık & Hastalıklı Alan & 10 & 13.6490 & 0.67821 & 0.21447 \\
\hline Ortalama & Sağlıklı Alan & 10 & 634.0800 & 31.72293 & 10.03167 \\
\hline Yağı̧ & Hastalıklı Alan & 10 & 559.8300 & 73.19883 & 23.14750 \\
\hline Ortalama En Yüksek & Sağlıklı Alan & 10 & 17.9620 & 0.29386 & 0.09293 \\
\hline Sıcaklık & Hastalıklı Alan & 10 & 18.6490 & 0.67821 & 0.21447 \\
\hline Ortalama En Düşük & Sağlıklı Alan & 10 & 9.1220 & 0.29386 & 0.09293 \\
\hline Sıcaklık & Hastalıklı Alan & 10 & 9.7880 & 0.65740 & 0.20789 \\
\hline
\end{tabular}

Şimşir ağaçlarında enfeksiyonun başladığı yıllar ile enfeksiyonun azaldığı yıllardaki iklim değerleri incelendiğinde (Çizelge 5), 2009 yılındaki meteorolojik değerlerde, yıllık ortalama minimum sıcaklık $8.9^{\circ} \mathrm{C}$, maksimum sıcaklık $24.9^{\circ} \mathrm{C}$, aylık ortalama sıcaklığın ise $12.7^{\circ} \mathrm{C}$ olduğu ve yılda ortalama $888.2 \mathrm{~mm}$ yağış aldığı görülmektedir. Bu yağış ve sıcaklık değerleri mantar hastalıklarının gelişmesine en uygun ortamdır. Şimşir yanıklığı hastalığı $5-30^{\circ} \mathrm{C}$ aralığında gelişmekte ve $19-25^{\circ} \mathrm{C}$ aralığında nemli koşullarda enfeksiyon hızlı bir şekilde yayılmaktadır 
Çizelge 5. Artvin ilii 2008-2019 yılları arasındaki meteorolojik değerler

\begin{tabular}{cccccc}
\hline Yıllar & $\begin{array}{c}\text { Ort. Minimum Sıcaklık } \\
\left({ }^{\circ} \mathrm{C}\right)\end{array}$ & $\begin{array}{c}\text { Ort. Maksimum Sıcaklık } \\
\left({ }^{\circ} \mathrm{C}\right)\end{array}$ & $\begin{array}{c}\text { Aylık Ortalama Sıcaklık } \\
\left({ }^{\circ} \mathrm{C}\right)\end{array}$ & $\begin{array}{c}\text { Ortalama Nispi Nem } \\
(\%)\end{array}$ & $\begin{array}{c}\text { Yıllık Toplam Yağış } \\
(\mathrm{mm})\end{array}$ \\
\hline 2008 & 8.5 & 25.5 & 12.4 & 61.6 & 600.4 \\
2009 & 8.9 & 24.9 & 12.7 & 57.7 & 888.2 \\
2018 & 10.1 & 28.0 & 14.5 & 64.3 & 576.4 \\
2019 & 10.0 & 26.9 & 13.7 & 61.1 & 426.5 \\
\hline
\end{tabular}

Topraktaki su durumu ile zararlı kabuk böceklerinin saldırılarına karşı ağaçların göstereceği direnç arasında doğrusal bir ilişki vardır (Nageleisen 2004a, 2004b). Kurak ve sıcak hava dalgaları; ağaçların biyotik ve abiyotik nedenlerle zayıf düşürülmesinde en önemli paya sahiptir. Bazı Avrupa ülkelerindeki plantasyonlarda ağaç türlerinin seçiminin isabetsiz olduğu, 2003 yılında görülen kuraklık sırasında anlaşılmıştır (Belrose ve ark. 2004, Rouault ve ark. 2006).

Mantar hastalıklarının bitkide enfeksiyon oluşturması için yüksek rutubet ve bitkinin ıslak olması yeterlidir (Henricot ve ark. 2000, Henricot ve ark. 2008).Artvin şimşir alanlarında mantarı hastalıklar 2010 yılında başlayarak birkaç yıl içinde geniş alanlara hızlı bir şekilde yayılmıştır. Mantarın gelişmesini ve üremesini etkileyecek ana kriter yağış oranlarının düşmesi ve kurak bir mevsimin hüküm sürmesi olarak düşünülebilir. 2009 ile 2019 yıllarında yıllık yağış miktarındaki 461.7 mm (Çizelge 3) bir farkın oluşması, Cy. pseudonaviculatum'un gelişmesini ve yayııma hızını sınırlamış olabilir

Şimşirler genellikle Doğu Karadeniz'de nemli, bol yağış alan habitatlarında, sarp ve kayalıklar üzerinde yayılış göstermektedirler. Bu alanlarda, kurak geçen yaz ve kış aylarından olumsuz yönde etkilenerek zayıf düşmektedirler. Fungal hastalıklar ve şimşir güvesi, bu olumsuz şartlar nedeniyle, yaklaşık 15 bin hektarlık alandaki şimşirlerin önemli bir bölümünü etki alanı içine almıştır.

Su stresine giren ve toprağın fakir olduğu, taşlık ve kayalık yerlerde yaşayan şimşir bitkisini strese sokmasının sonucu olarak Artvin Bölge Müdürlüğü şimşir ormanlarında zayıf düşen bu ağaçlarda2015 yılında C. perspectalis'in zararı görülmeye başlanmıştır (Aksu 2019). Larvaların tüm yaprakları ve taze sürgünler ile gövdenin kambiyum tabakasını yedikleri görülmüştür. Tırtılların kambiyuma verdikleri zarar nedeniyle Şimşir yaprak yanıklığı hastalığının yayılmasına da neden olmaktadır.

\section{SONUÇ VE ÖNERILER}

Cy. pseudonaviculatum ve Cydalima perspectalis zararlıları Artvin Bölge Müdürlüğü şimşir ormanlarının tamamına yakın bir kısmının ölümüne neden olmuştur. Ancak şimşirlerin kurumalarına neden olan en önemli etkenin $C y$. pseudonaviculatum, mantarı olduğu düşünülmektedir.

Sahalardan alınan toprak tahlillerinin analizleri sonucunda, sağlıklı şimşir alanları ve hastalıkı şimşir alanlar arasında toprak özellikleri bakımından farklılık olmadığı, diğer bir ifadeyle hastalığın oluşumunda toprak özelliklerinden kaynaklanan bir etkinin olmadığı sonucuna varılmıştır.

Şimşir ormanlarındaki ağaç ölümlerine neden olan $C y$. pseudonaviculatum'un yayılmasının ve tüm şimşir ormanlarımızı enfekte etmesinin, ana sebeplerinin başında yağış ve sıcaklığın etkisinin olduğu düşünülmektedir. Kurumaların yoğun olduğu alanlarda sağ ııkı alanlara göre ortalama sıcaklıkların yüksek, yağışın ise düşük olmasının bu etkiyi doğruladığı söylenebilir.

Doğal şimşir ormanlarının yeniden tesis edilmesi için, hayatta kalan ve dayanıklı şimşir bireylerinden alınan örneklerden çelikten veya tohumdan üretim yapılarak, mantarın canlı olma özelliğini kaybettiği sahalara dikilmesi ile doğal şimşir ormanlarının yeniden kurulmasına yardımcı olacaktır. 


\section{TEŞEKKÜR}

Şimşir fungal hastalıklarının ve Şimşir kelebeğinin teşhisi ile değerlendirmesinde vermiş olduğu destekten dolayı Biyolog Yaşar Aksu'ya teşekkür ederim.

\section{KAYNAKLAR}

Aksu Y (2019) Doğu Karadeniz Tarım ve Orman Alanlarına Yeni Giriş Yapan Zararlı Organizmalar. Orman ve Av Dergisi, 2: (97), 41-47.

Altunışık A, Oskay F, Aday Kaya AG, Lehtijärvi A, Doğmuş Lehtijärvi HT (2017) Şimşirlerimiz üzerinde yeni bir tehdit: Şimşir Yanıklığı. Orman ve Av. 2: (95), 43-46.

Ateş K, İpek A, Yıldız Ş (2010) Trabzon Orman Bölge Müdürlüğü’ndeki Şimşir Potansiyeli ve Kullanımı, III. Ulusal Karadeniz Ormancılık KongresiCilt: III, 1134-1143.

Belrose V, Nageleisen LM, Renaud JP (2004) Lesconséquences de la canicule et de la sécheresse sur la santédesforêts: bilan à la fin de l'année 2003. La santédesforêts (France) en 2003.

BentzBJ, Régniére J, Fettig CJ, MatthewHanse E, Hayes JL, Hicke JA, Kelsey, RG, Negron JF, Seybold SJ (2010) Climate Changeand Bark Beetles of the Western United Statesand Canada: Direct and Indirect Effects. Bio Science. 60: 602-613.

Burjanadze M, Supatashvili A, Göktürk T (2019) Control strategies against invasive pest Box Tree Moth - Cydalima perspectalisin Georgia" 3rd International Symposium on Innovative Approaches in Scientific Studies Section: Engineering and Natural Sciences, Ankara / Turkey, 19-21 April SETSCI, Conference Proceedings. 4(1): 1-4.

Christiansen E, Bakke A (1997) Integrating cultural tactics into the management of bark beetle and reforestation pests. in: Grégoire, J.C., Liebhold, A.M., Stephen, F.M., Day, K.R., Salom, S.M. (Eds.), General Technical Report. USDA Forest Service, pp. 163-171.

Eminağaoğlu Ö, Anşin R (2003) The Flora of Hatila Valley National Park and its close Environs (Artvin). Turkish Journal of Botany. 27(1): 127.

Eminağaoğlu Ö, Yüksel E, Akyıldırım Beğen H (2018) Flora of the Hod Valley (Artvin, Turkey). International Journal of Ecosystems and Ecology Science-IJEES. 8 (2): 273-282.

Göktürk T, Aksu Y (2014) Hatila Milli Parkında Tespit Edilen Lepidoptera Türleri. Türkiye II. Orman Entomolojisi ve Patolojisi Sempozyumu, 7-9 Nisan, Sempozyum Kitabı, 607-615, Antalya.

Göktürk T (2017) The Effect of Dipeland Spruzit Against Cydalima perspectalis (Walker, 1859) (Lepidoptera: Crambidae), International Forestryand Environment Symposium "Climate Changeand Tree Migration" 7-10 November 2017, AbstractBook, p. 125, Trabzon, Turkey.

GülçurF (1974) Toprağın Fiziksel ve Kimyasal Analiz Metodları. i..Ü. Orman Fakültesi Yayınları, No: 201, i̇stanbul.

Hanks LM, Paine TD, Millar JG, Campbell CD, Schuch UK (1999) Waterrelations of hosttreesandresistancetothephloemboringbeetlePhoracanthasemipunctataF. Cerambycidae). Oecologia, 119: 400-407.
Henricot B, Gorton C, Denton G, Denton J (2008) Studies on the control of Cylindrocladium buxicola using fungicides and host resistance. Plant Disease. 92(9): 1273-1279.

Henricot B, Pérez Sierra A, Prior C (2000) A new blight disease on Buxusin the UK caused by the fungus Cylindrocladium. Plant Pathology.49(6): 805.

Hızal E, Köse M, Yeşil C, Kaynar D (2012) The New Pest Cydalima perspectalis (Walker, 1859) (Lepidoptera: Crambidae) in Turkey. Journal of Animal and Veterinary Advances, 11 (3): 400-403.

Irmak A (1972) Toprak İlmi. ï Orman Fak. Yay. No 184, i̇stanbul.

Laz B, Babür E, Akpınar DM, Avgın SS (2018) Kahramanmaraş-Elmalar Yeşil Kuşak Ek-3 Plantasyon Sahasında Görülen Biyotik ve Abiyotik Zararlıların Tespiti. KSÜ Tarım Doğa Dergisi, 21(6) : 926-935.

Lehtijärvi A, Doğmuş Lehtijärvi HT, Oskay F (2014). Cylindrocladium buxicolais Threatening the Native Buxus sempervirens Populations in Turkey. Plant ProtectionScience, 50: (4), 227-229.

Leuthardt FLG, Billen W, Baur B (2010) Spread of the box-tree pyralid Diaphania perspectalis (Lepidoptera: Pyralidae) in the region of Basel-a pests pecies new for Switzerland. Entomo Helvetica, (3): 51-57.

Nageleisen LM (2004a) Les insectes sous-corticaux des résineux en 2002: diminution inattendue des dommages dus aux scolytes. Min.Agri. Alim. Pêche Aff. Rur. (DGFAR), Paris.

Nageleisen LM (2004b) Recrudescence des insectes sous-corticaux à la suite des extrêmes climatiques de 2003, in: Bilan de lasanté des forêts en 2003, Min. Agri. Alim. Pêche Aff. Rur., Paris.

Öner N, Şimşek Z, Kondur Y, İmal B, Şimşek M (2010) Küresel iklim değişikliği dikkate alınarak kurak ve yarı kurak alanların ağaçlandırılması ve zararlı böceklerle mücadelesine yönelik öneriler (Çankırı ili örneği). In, III. Ulusal Karadeniz Ormancılık Kongresi, Artvin, 827-838.

Rouault G, CandauJN, Lieutier F, Nageleisen LS, Martin JC, Warzée N (2006) Effects of Drought and Heat on Forest Insect Population in Relation to the 2003 Drought in Western Europe. Ann. For. Sci. 63: 613-624.

Seljak G (2012) Six new alien phytophagous insect species recorded in Slovenia in 2011. Acta Entomologica Slovenica, 20: 31-44.

Semerci A, Çelik O, Şanlı B, Şahin Ö, Eczacıbaşı B, Argun N (2006) iç Anadolu Bölgesinde Son Beş Yılda İncelenen Bazı Ağaç Kurumalarının Nedenlerinin İncelenmesi ve Çözüm Önerileri. Türkiye'de Yarı kurak Bölgelerde Yapılan Ağaçlandırma ve Erozyon Kontrolü Uygulamalarının Değerlendirilmesi Çalıştayı, 7-10 Kasım 2006 Ürgün, Nevşehir, 52-53.

Symmes H (1984) Mail Box, the Amerikan Boxwood society, The Boxwood Bulletin, April Boyce. 24, 4.

Şimşek Z, Kondur Y, Şimşek M (2006) Küresel İklim Değişikliğinin Zararlı Böcekler Üzerine Olası Etkileri. In, IV. Çankırı Kültürü Bilgi Şöleni, Çankırı, 87-125.

Şimşek Z, Kondur Y, Şimşek M (2010a) Küresel İklim Değişikliğinin Kabuk Böcekleri Üzerinde Beklenen Etkileri. Biyoloji Bilimleri Araştırma Dergisi. 3; 149-157.

Şimşek Z, Öner N, Kondur Y, Şimşek M (2010b) Kuraklığın Orman Biyoçeşitliliği Üzerine Etkileri ve Gelecekte Alınması Gereken Önlemler. In, Çölleşme ile Mücadele Sempozyumu, Çorum, Türkiye, 514-521 
Şimşir ormanlarında bazı toprak ve iklim özelliklerinin Cylindrocladium pseudonaviculatum'in epidemi oluşturması üzerine etkilerin araştırılması: Taşlıca ve Tütüncüler örnekleri

Türkyılmaz E, Vurdu H (2003) Şimşirin (Buxus spp.) genel özellikleri, Gazi Üniversitesi Kastamonu Orman Fakültesi Dergisi, 3: 65-172.

URL

https://atib.ogm.gov.tr/Sayfalar/T\%C4\%B1bbi\%20ve\%20ltri\%20B
itkilerimizi\%20Tan\%C4\% B1 yal\%C4\% B1m/Simsir.aspx (02.04.2020). .

Williams DW, Liebhold AM (2002) Climate change and the outbreak ranges of two North American bark beetles. Agricultural and Forest Entomology. 4: 87-9 